\title{
Environmental and digital competencies in the education of engineering specialists
}

\author{
Vladimir Popov, Natalya Klycheva, Julia Bolandova, Eugene Asmankin, and Philipp \\ Sukhov $^{*}$ \\ Russian University of transport (MIIT), Moscow, Russian Federation
}

\begin{abstract}
The article discusses the acquisition of environmental and related digital competencies in the training of engineering specialists of different levels. Provides data on current trends in education. The approaches to basic, universal and general technical competencies, and their relationship with digital competencies are considered. When working with expert opinions, the necessary, in the opinion of the expert community, environmental and digital competencies that are relevant in modern conditions are identified. Based on these results, changes were proposed to the work program for the discipline related to ensuring environmental safety on the one hand and digital competencies on the other. Based on a review of modern approaches, a survey of experts and work with new generation work programs, conclusions were drawn about the advisability of continuing research in this direction, as well as the implementation of digital competencies in the field of environmental education.
\end{abstract}

\section{Introduction}

Digital transformation is one of the main drivers of global economic growth. According to the McKinsey Global Institute, in China, up to $22 \%$ of the increase in GDP by 2025 may be due to Internet technology. In the United States, the expected increase in the value of digital technologies, by 2025 could reach 1.6-2.2 trillion US dollars according to conservative estimates.

In modern conditions of training students in engineering areas, an important factor is their acquisition of competencies in interdisciplinary areas. A modern engineering and technical specialist must have a wide range of competencies in mathematical, physical, chemical, legal, economic and other areas. Without possessing these competencies, it is difficult to train specialists who are ready to meet the challenges of the time in a timely manner. In the context of the inevitable transition to Industry 4.0, the engineer of the future must be able to quickly adjust his professional trajectory. The possibility of such adjustment for a specialist, on the one hand, will make it possible to implement a wide competence base, and on the other hand, modern, digital, technologies in training [1] and in work.

The concept of the fourth industrial revolution is based on four principles [2]:

- Functional compatibility of man and machine - the ability to contact directly via the Internet;

\footnotetext{
*Corresponding author: philipp@sukhov.org
} 
- Transparency of information and the ability of systems to create a virtual copy of the physical world;

- Technical assistance of machines to humans - combining large amounts of data and performing a number of tasks unsafe for humans;

- The ability of systems to independently and autonomously make decisions.

\section{Materials and methods}

The use of digital competencies in undergraduate and graduate programs was considered as part of the competencies of teachers and staff, and as the competencies necessary to obtain for students.

Professional competencies in the field of digital development are understood as a group of competencies associated with the functional use of methods and tools for managing processes, projects, digital transformation products and the regular solution of complex professional tasks in the digital environment.

All digital competencies required by workers in modern production, from workers to specialists, can be divided into four groups according to the level of complexity and the type of tasks to be solved (Figure 1 [3]).

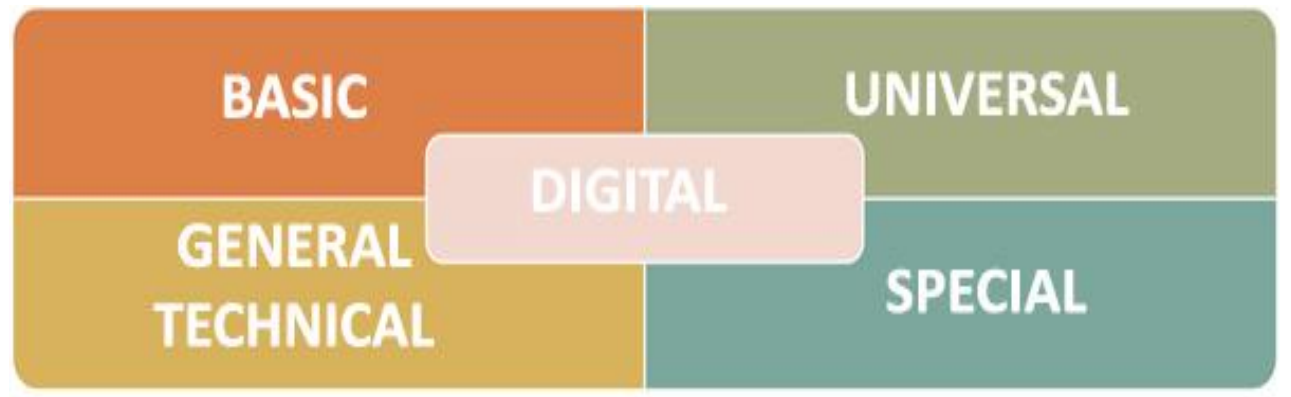

Fig. 1. The structure of digital competencies.

Basic competencies were those related to basic scientific knowledge in mathematical, physical, chemical, historical, philosophical and similar fields in this study.

Universal competences include competencies related to soft-skills areas, as well as competencies in the field of general management, team building, legal literacy, etc.

General technical competences included competences in the field of general engineering disciplines: electrical engineering, metrology, engineering graphics and the like.

Special (sectoral) competencies, in this work, were competences in the transport area.

As can be seen from Figure 1, in modern conditions, all types of competencies are closely related to digital competencies.

Digital competencies [4] (hereinafter referred to as DC) are a set of competencies for working in a digital environment and with digital products, including the activity of creating and collecting data, processing and analyzing them, as well as automating processes using computer technologies.

There are five levels of mastering the DC:

- Initial;

- Basic;

- Advanced;

- Professional;

- Expert. 
Each next level is the development of the previous one in terms of the volume of skills as the ability to solve a wider range of problems.

The professional and expert levels of DC development do not belong to the mass, they are not the minimum necessary, they are achieved within the framework of special disciplines (senior bachelor's and magistrate courses), as well as in the process of improving the professional trajectory in the course of advanced training and professional training.

For the possibility of obtaining and developing competencies in the field of DC, basic knowledge in the field of digital literacy is required, which students should receive in the process of school or secondary vocational education.

Digital literacy (hereinafter referred to as DL) is technical and cognitive skills that allow one to navigate in modern information technologies, satisfying personal, educational and professional needs.

Examples of such skills are:

- The ability to work with information in a digital environment,

- The ability to algorithmize and optimize their actions,

- The ability to interact in the digital environment, taking into account the norms of ethics and legal regulation of the digital space,

- knowledge of the basics of information security at the user level and the ability to protect digital devices and personal data,

- understanding the technical capabilities of modern digital devices and Internet technologies, the ability to solve simple technical problems,

- ability to work in office applications, etc.

According to [4], for each educational program, it is necessary to fix the minimum threshold for mastering the DC, for the possibility of training on this program.

For the teaching staff, the key characteristics of professional competencies in the field of digital development are knowledge, skills and application skills:

- tools, methods and approaches of strategic management in digital development management (political, economic, technological trends in the world and in Russia; management levels: strategic, tactical, operational, and their relationship, etc.);

- the basics of the digital economy (organization and management of economic activities in the process of digital transformation; the system of public administration focused on digital and electronic technologies; general provisions of the national program "Digital Economy");

- digital public administration technologies (digital transformation strategy and an integrated digital transformation roadmap; implementation of digital technologies and platform solutions; ethics of the digital world, international and Russian legislation; the concept of "state as a platform");

- tools for assessing the digital maturity / manufacturability of the public administration system (maturity criteria; monitoring, analyzing and forecasting the progress of digital transformation; prioritizing digital development initiatives).

\section{Results}

A number of experts working in industry companies were interviewed during the study. The experts were asked the following questions:

- What professional competencies are needed for modern specialists in the field of ensuring environmental safety at the levels of undergraduate and graduate education?

- What environmental competencies are needed for modern engineering and technical and related specialists in the field of environmental safety at the bachelor's and master's degrees? 
- What digital competencies are needed for modern specialists in the field of environmental safety at the bachelor's and master's degrees?

The experts represented the transport, industrial and environmental sectors. The questions were posed in an open form, so it is not possible to formalize the results. During the review of expert responses, a number of duplicate results were obtained, which are summarized in a general form in Table 1.

Table 1. Environmental and digital competencies

\begin{tabular}{|c|c|c|c|}
\hline № & $\begin{array}{c}\text { Generalized formulation } \\
\text { of competence }\end{array}$ & Type of specialist & Type of competence \\
\hline 1 & $\begin{array}{c}\text { Energy and resource } \\
\text { conservation competencies }\end{array}$ & Ecologists / Engineers & Environmental \\
\hline 2 & $\begin{array}{l}\text { Alternative Energy } \\
\text { Competence }\end{array}$ & Ecologists & Environmental \\
\hline 3 & $\begin{array}{l}\text { Chemical safety } \\
\text { competencies }\end{array}$ & Ecologists / Engineers & Environmental \\
\hline 4 & $\begin{array}{l}\text { Competence in the field of } \\
\text { digitalization of } \\
\text { environmental safety } \\
\text { Environmental }\end{array}$ & Ecologists / Engineers & Digital / Environmenta \\
\hline 5 & $\begin{array}{l}\text { Management System } \\
\text { Competencies * }\end{array}$ & Ecologists & Environmental \\
\hline 6 & $\begin{array}{l}\text { Carbon Neutrality } \\
\text { Competencies }\end{array}$ & Ecologists & Environmental \\
\hline
\end{tabular}

Table 1 shows generalized wording, which is related to the open form of the questions. Table 1 presents only new competencies, traditional (classical) competencies are not included in the table. Most experts express the idea that abandoning classical basic competencies is not advisable, since they are the basis for the development of modern competencies, and also provide an opportunity for a variable educational trajectory at all levels of education.

Based on the answers of the experts, as well as taking into account the data of the course [5], changes were made to the work program of the discipline "Information technology in the field of environmental safety." This discipline is taught to masters of the first year of study under the master's program 20.04.01 Technosphere safety, Environmental management. To ensure the "digital" requirements, the following sections were added to the program:

- Section 3. Modern IT solutions in the field of remote interaction of employees;

- Section 4. Application of information technologies in the context of rapidly changing business factors;

- Section 6. Cloud technologies.

- The above sections were added based on the following prerequisites:

- Section 3. Gains particular relevance in the context of the transition to Industry 4.0, as well as the functioning of companies during the COVID-19 pandemic [6]. Modern business processes, including industrial production, transport and other activities, are impossible without constant interaction of personnel with each other and counterparties. The arsenal of tools provided by today's IT solutions is truly enormous. The practitioner should be familiar with these applications and environments.

- Section 4. Modern business environment, chaotic and rapidly changing - a new reality. This reality is forcing companies to transform their approach to business processes. This reality is called VUCA world (table 2). 
Table 2. VUCA world

\begin{tabular}{|c|c|c|}
\hline № & Name & Explanation \\
\hline 1 & Volatility & $\begin{array}{l}\text { Characterizes unstable situations and unpredictable changes - in } \\
\text { nature, speed, volume, dynamics. The duration of this state of } \\
\text { affairs is unclear. Most companies are now operating in an } \\
\text { environment of market and political instability and are forced to } \\
\text { take into account rapidly changing circumstances. }\end{array}$ \\
\hline 2 & Uncertainty & $\begin{array}{l}\text { Characterizes the lack of information for predicting the } \\
\text { consequences and planning the necessary actions. What was } \\
\text { previously considered indisputable has lost its power, and } \\
\text { decision-making cannot be completely based on past experience. }\end{array}$ \\
\hline 3 & Complexity & $\begin{array}{l}\text { Takes into account situations where there are many interrelated } \\
\text { elements and a huge amount of information. Such a large number } \\
\text { of factors greatly complicates the decision-making and planning } \\
\text { process. For example, international rules for the transport of } \\
\text { dangerous goods, with the specificity of each country or the } \\
\text { transboundary transfer of impurities. }\end{array}$ \\
\hline 4 & Ambiguity & $\begin{array}{l}\text { Determined by the lack of a clear understanding of the rules of the } \\
\text { game. Sometimes this is due to situational novelty and doubts that } \\
\text { can arise when trying to make decisions in a new context. } \\
\text { Transition from the submission of environmental reports on paper } \\
\text { to their introduction into the information systems of regulatory } \\
\text { authorities using an electronic signature. }\end{array}$ \\
\hline
\end{tabular}

The rate of change in many industries is now much faster than it was ten or twenty years ago. With digital technology and changing customer needs, this increased volatility is real for many companies. Risk assessment [7 - 9] and modeling under uncertain conditions [10] are an important part of being in the VUCA world.

In such a reality is necessary to carry out their professional activity of specialists in all sectors of the economy today.

- Section 6. Cloud services is your work site on remote servers, which provides various services for the implementation of professional goals, tasks, projects. Cloud technologies today are advanced solutions in the field of digitalization of the economy and public administration.

Today a large-scale project "Gostech" is being implemented in Russia. The Gostech platform should replace the typical components of government IT systems: logging, monitoring, BPM, load balancing, authentication and authorization, streaming event processing, etc. cloud-based.

The provision of various digital services in different areas is often based on cloud technologies [11]. It is difficult to imagine a modern engineering specialist, including in the field of environmental safety, who does not use digital technologies to one degree or another. Therefore, it is important to provide competencies for the use of these services in their professional activities to all engineering students.

The inclusion of these sections in the work program of the discipline will allow to continue to develop digital competencies among masters studying in the program "Environmental Management". The acquired competencies will increase the value of specialists in the labor market, and given the breadth of the information provided, they will allow, if necessary, to adjust their professional trajectory with the least expenditure of financial resources, time and mental energy. 


\section{Conclusion}

The modern educational process is being implemented in the context of constant changes. The training of specialists in any field must meet the requirements of tomorrow in soft and hard skills area. The basis for the creation of a "specialist of the day after tomorrow" can be an alloy of deep basic training to ensure the breadth of knowledge that he can acquire and the use of digital solutions, both in the educational process and as newly acquired competencies. In addition, deep practical training, including project activities, is extremely important. Based on the results of the study, a number of conclusions can be drawn.

Interdisciplinary competencies play an important role in the training of engineering personnel today.

Environmental competencies can be largely attributed to basic competencies for engineering professionals. Digital competencies should also be attributed to the competencies that are required and promised in most areas and programs of higher education.

In the preparation of bachelors and masters in the environmental focus is necessary to take into account changes occurring in the field of environmental protection in the Russian and international level.

According to the results of the work with the expert community are revealed expired today competence. A number of experts from the transport and environmental sectors note the need to introduce the professional standard "Specialist in environmental safety (in transport)", this is due to the peculiarities of technological processes in the transportation of goods and passengers.

\section{References}

1. N.A. Klycheva, E.S. Prokof'eva, C.C. Andrijanov, Strategic orientations of the development of higher education. Collection of scientific papers of the participants of the National Scientific and Practical Conference, 39 (2019)

2. I.V. Tarasov, Business strategies, 57 (2018)

3. O.V. Spiridonov, Accounting for digital technologies in professional standards, 1 (2020)

4. Concept for the development of digital competencies in HSE students, 01 (2020)

5. Refresher courses for teachers of higher and secondary vocational education on new programs for IT specialties and various subject areas (Kazan, 2021)

6. A.N. Koroleva, A.S. Sachkova, Occupational Medicine and Industrial Ecology, 804 (2020)

7. V. Popov, P. Sukhov, J. Bolandova, TransSiberia 2019: VIII International Scientific Siberian Transport Forum, 899 (2019)

8. L.A. Koroleva, A.G. Hajdarov, Introduction of chemical exergy in the assessment of fire risk of freight transport by rail, XXX International Scientific and Practical Conference. 2019 Problems and prospects of fire-technical expertise and supervision in the field of fire safety, 30 (2019)

9. Bianca Borca, Lisa-Maria Putz, Florian Hofbauer, Sustainability, 13(10), 1 (2021)

10. N.K. Volosova, A.K. Volosova, K.A. Volosov, S.P. Vakulenko, Mathematical Models and Computer Simulations, 12, 246 (2020)

11. A. Abashev, R. Grigoryev, K. Grigorian, V. Boyko, BioNanoScience, 7, 403 (2017) 